\title{
Kunecatechins Ointment
}

National Cancer Institute

\section{Source}

National Cancer Institute. Kunecatechins Ointment. NCI Thesaurus. Code C67049.

A topical ointment containing a green tea polyphenol mixture (kunecatechins) with potential antiviral, antibacterial, antioxidant, and chemopreventive activities.

Kunecatechins is a partially purified fraction of the aqueous extract of green tea leaves from Camellia sinensis and contains catechins and other green tea components. Catechins, polyphenolic antioxidant plant metabolites or flavonoids, comprise most of the drug substance in kunecatechins with epig allocatechin gallate (EGCG) present as the primary catechin. Catechins may inhibit basic functions of human papillomavirus (HPV), counteract specific changes in tumor cells, affect cell signaling, and stimulate the immune system. Topical application of kunecatechins ointment has been reported to reduce HPV-induced genital and anal warts through a not yet fully understood mechanism, which may involve anti-oxidative activity. 